The Plant Endoplasmic Reticulum

(Print ISBN: 978-1-4939-7388-0, online ISBN: 978-1-4939-7389-7)

Chapter 1: Labeling the ER for Light and Fluorescence Microscopy 


\section{Labelling the ER for light and fluorescence microscopy}

Chris Hawes ${ }^{1}$, Pengwei Wang ${ }^{2 \pm}$, Verena Kriechbaumer ${ }^{1}$

${ }^{1}$ Plant Cell Biology, Biological and Medical Sciences, Oxford Brookes University, OX3 OBP

Oxford, UK

${ }^{2}$ Department of Biosciences, Durham University Durham DH1 3LE, UK

${ }^{ \pm}$Current address: College of Horticulture and Forestry Sciences, Huazhong Agricultural University, Wuhan 430070, Hubei Province, China

\section{Abstract}

The ER is a highly dynamic network of tubules and membrane sheets. Hence imaging this organelle in its native and mobile state is of great importance. Here we describe methods of labelling the native ER using fluorescent proteins and lipid dyes as well as methods for immunolabelling on plant tissue.

Key words: endoplasmic reticulum, labelling, fluorescent protein, stable, transient expression, immunofluorescence, fluorescent dyes

\section{Introduction}

The endoplasmic reticulum (ER) forms a dynamic, continually changing network of tubules and membrane sheets or cisternae that ramify throughout the cytoplasm of cells. As such in order to appreciate its true nature it is often necessary to image the organelle in its native state in living cells. For convenience it is often best to think of the ER as two interconnected populations of tubules and cisternae. Firstly, there is the geometrical cortical network overlies the cortical cytoskeleton and is connected to the plasma membrane at specific contact points (1). Secondly, cytoplasmic ER often rapidly streams and also transverses the vacuolar lumen via transvacuolar strands. 
Two strategies are available for imaging the ER in its native form. A number of different probes have been used to directly label the ER in living cells. Most of them are not one hundred percent specific for the ER membrane and may label other organelles at varying concentrations and incubation times. Two probes with different emission wavelengths which are relatively easy to use on a range of plant tissues are the rhodamine B hexyl ester (2) and 3,3'-dihexylocarbocyanine iodide (DiOC6, green emission) $(3,4)$ Expression of fluorescent protein constructs which are targeted to the ER is another efficient strategy for in vivo labelling. It is possible to use labelled proteins or peptide sequences that are targeted to the ER membrane $(5,6)$; although on occasions these can perturb the membrane and alter the structure of the ER network $(5,7)$. Alternatively a simple construct comprising a signal sequence and fluorescent protein with a KDEL or HDEL retrieval motif splices to the $\mathrm{C}$ terminus is sufficient to label the lumen of the ER and is often the construct of choice $(8,9)$.

Immunocytochemistry is an important technique for locating native proteins and confirming the validity of the location of fluorescent protein constructs. Many different preparative techniques for the immunofluorescence labelling of plant proteins have been described over the years, including, production of single cells by enzyme digestion (the root squash technique), cryo-sectioning, wax or resin embedding and sectioning (10). Here we describe a modification of the root squash technique to permeabilise root tip cells and the freeze shatter technique developed by Wasteneys et al (11) that permits the physical rupture of Arabidopsis tissues and cells, permitting antibody penetration and is particularly suitable for Arabidopsis seedling tissues.

In this chapter we describe the following methods:

a) Agrobacterium mediated transient protein expression in tobacco epidermal leaf cells

b) Stable protein expression in tobacco

c) Stable protein expression in arabidopsis

d) Immunofluorescence in arabidopsis roots 
e) Freeze-shattering and immunofluorescence

f) The use of lipid dyes Rhodamine B hexyl ester or $\mathrm{DiOC}_{6}$

\section{Materials}

2.1 Solutions and equipment

2.1.1 For Agrobacterium mediated transient protein expression in tobacco epidermal leaf cells

1 YEB medium: $5 \mathrm{~g} / \mathrm{l}$ of beef extract, $1 \mathrm{~g} / \mathrm{l}$ of yeast extract, $5 \mathrm{~g} / \mathrm{l}$ of sucrose, $0.5 \mathrm{~g} / \mathrm{l}$ of $\mathrm{MgSO}_{4} \cdot 7 \mathrm{H}_{2} \mathrm{O}$.

2 Infiltration buffer: $50 \mathrm{mM} \mathrm{MES}, 2 \mathrm{mM} \mathrm{Na} 3 \mathrm{PO}_{4} \cdot 12 \mathrm{H}_{2} \mathrm{O}, 0.1 \mathrm{mM}$ acetosyringone and 5 $\mathrm{mg} / \mathrm{ml}$ glucose.

3 Water bath

4 Nanodrop spectrophotometer (or equivalent) to determine optical density of bacterial culture

\subsubsection{For stable protein expression in tobacco}

1 Sterilization solution: 1:1 hypochlorite solution : $\mathrm{dH}_{2} \mathrm{O}, 0.01 \%(\mathrm{v} / \mathrm{v})$ Tween 20 .

2 Plates with shooting medium: $2.15 \mathrm{~g} / \mathrm{l}$ Murashige and Skoog salts, pH 5.2 (without IAA, kinetin or sucrose; MP Biomedicals Inc.), $0.8 \%$ (w/v) agar, 3.0\% (w/v) sucrose, $0.1 \mathrm{mg} / \mathrm{l}$ indole butyric acid (1.0 mg/ml stock), $0.8 \mathrm{mg} / \mathrm{l}$ 6-benzylaminopurine (1.0 mg/ml stock), $0.1 \mathrm{mg} / \mathrm{l}$ carbenicillin, $0.2 \mathrm{mg} / \mathrm{l}$ Ticarcillin/Clavulanic acid (Ducheva) and suitable selection for the binary vector carrying your FP fusion construct. Dissolve Murashige and Skoog salts and sucrose in ultrapure deionized water. Add stock solutions of plant growth regulators. Adjust the $\mathrm{pH}$ to 5.2 and autoclave. When the medium has cooled to $50^{\circ} \mathrm{C}$, add filter-sterilized antibiotics and pour into Petri dishes. Plates are kept at $4^{\circ} \mathrm{C}$ in the dark. 
3 Plates with rooting medium: $2.15 \mathrm{~g} / \mathrm{l}$ Murashige and Skoog salts, $0.8 \%(\mathrm{w} / \mathrm{v})$ agar, 3.0\% (w/v) sucrose, $0.5 \mathrm{mg} / \mathrm{l}$ indole butyric acid ( $1 \mathrm{mg} / \mathrm{ml}$ stock), $0.1 \mathrm{mg} / \mathrm{l}$ carbenicillin, $0.2 \mathrm{mg} / \mathrm{l}$ Ticarcillin/ Clavulanic acid (Ducheva).

\subsubsection{For stable protein expression in arabidopsis}

1 LB broth: Tryptone $10 \mathrm{~g} / \mathrm{l}, \mathrm{NaCl} 10 \mathrm{~g} / \mathrm{l}$ Yeast extract $5 \mathrm{~g} / \mathrm{l}$

2 Dipping buffer: $5 \%$ sucrose, $50 \mu \mathrm{l} / \mathrm{l}$ Silvet $\mathrm{L}-77$ in $\mathrm{dH}_{2} \mathrm{O}$

\subsubsection{For immunofluorescence in arabidopsis root cells}

1 MBS ester (m-maleimidobenzoyl-N-hydroxysuccinimide)

2 Fixative: paraformaldehyde (PFA) 4\%, glutaraldehyde 0.5\%, EGTA 5mM (pH 8.0), PIPES $50 \mathrm{mM}(\mathrm{pH} 7.0), \mathrm{MgSO}_{4} 2 \mathrm{mM}, 0.01 \%$ Triton X-100 0.01\% (see Note 1).

3 PBS buffer ( $\mathrm{pH} 7.4)$

4 Blocking buffer: PBS supplemented with $2 \%$ BSA

5 Permeable buffer: PBS supplemented with $0.1 \%$ Triton X-100

6 Dricelase solution: Dricelase (2\%) in PBS.

7 Proteinase inhibitors: PMSF, leupeptine and pepstatine A

8 Liquid nitrogen

9 Metal block and a hammer

10 Glass Microscope slide

11 Plastic Sieves

12 Vectashield

2.1.5 For Freeze-shattering and immunofluorescence

1 MBS ester (m-maleimidobenzoyl-N-hydroxysuccinimide)

2 PBS buffer

3 Blocking buffer: PBS supplemented with $2 \%$ BSA

4 Permeable buffer: PBS supplemented with $0.1 \%$ Triton X-100 
5 Driselase solution: Driselase (2\%) in PBS.

6 Proteinase inhibitors: PMSF, leupeptine and pepstatine A

7 Liquid nitrogen

8 Metal block and a hammer

9 Glass Microscope slide

10 Plastic Sieves

11 Vectashield or equivalent anti-fade mountant

2.1.6 For lipid dyes Rhodamine B hexyl ester or $\mathrm{DiOC}_{6}$.

1 Rhodamine B hexyl ester solution: stock solution1 mM in DMSO, working solution $1 \mu \mathrm{M}$ in water

$2 \mathrm{DiOC}_{6}$ (Molecular Probes): working solution: $1.8 \mathrm{mM}$ in water.

$32 \mathrm{ml}$ Eppendorf tubes

\subsection{Antibodies for immunofluorescence}

Various suppliers are possible for both primary and secondary antibodies.

1. Polyclonal mouse antibody against VAP27-1 (12)

2. Polyclonal mouse antibody against NET3C (1)

3. Polyclonal Rabbit antibody against BIP2 (Agriserum)

4. Polyclonal Rabbit antibody against HDEL (Agriserum)

5. Goat-anti-rabbit FITC conjugated antibody (Immuno jackson)

6. Goat-anti-mouse TRITC conjugated antibody (Immuno jackson)

\subsection{Microscopy}

1 Upright or inverted laser scanning or spinning disc confocal microscope, TIRF microscope, super resolution fluorescence microscope.

\section{Methods}


3.1 Agrobacterium-mediated transient expression in tobacco epidermal leaf cells

3.2 stable protein expression in tobacco

3.3 stable protein expression in arabidopsis

3.4 Immunofluorescence in arabidopsis root

3.5 Freeze-shattering and immunofluorescence

3.6 Labelling of ER with lipid dyes

Table 1. Some suggested constructs suitable for imaging the ER in epidermal cells.

\begin{tabular}{|l|l|l|}
\hline Construct & Comments & Reference \\
\hline SS-FP-HDEL & Labels ER lumen & $(8)$ \\
\hline Reticulon-FP & $\begin{array}{l}\text { Labels membrane of ER tubules and } \\
\text { cisternal rims. Over-expression can } \\
\text { constrict tubules }\end{array}$ & $(5)$ \\
\hline Calnexin-TMD-FP & Membrane marker - can induce cisternae & $(6)$ \\
\hline Derlin-FP & on high expression & $(7)$ \\
\hline
\end{tabular}

3.1 Agrobacterium-mediated transient expression in tobacco epidermal leaf cells

1. For Agrobacterium-mediated transient expression, 5-week-old tobacco (Nicotiana tabacum SR1 cv Petit Havana) plants grown in the greenhouse are used. Transient expression is carried out according to Sparkes et al. (2006) (13). Alternatively $N$. benthamiana plants are also suitable for transient expression experiments.

2. Construct a suitable expression vector using standard molecular biology techniques such as conventional Cut\&Paste cloning (14) or Gateway cloning $(15,16)$ 
3. Introduce the expression vector into Agrobacterium strain GV3101 by heat shock.

4. Inoculate transformants into $5 \mathrm{ml}$ of YEB medium with the appropriate antibiotic for the bacterial vector used as well as $25 \mathrm{mg} / \mathrm{l}$ rifampicin.

5. After overnight shaking at $28^{\circ} \mathrm{C}$, pellet $1 \mathrm{ml}$ of the bacterial culture by centrifugation at $2000 \mathrm{~g}$ for $5 \mathrm{~min}$ at room temperature.

6. Wash the pellet twice with $1 \mathrm{ml}$ of infiltration buffer and then resuspended in $1 \mathrm{ml}$ of infiltration buffer.

7. Initially dilute the bacterial suspension to a final $O D_{600}$ of 0.1 . If expression is successful then different $O D_{600}$ values can be tested to improve the expression results, or to reduce expression levels, such as $\mathrm{OD}_{600}$ of 0.05 or 0.01 .

8. Carefully press the suspension is through the stomata on the lower epidermal surface using a $1 \mathrm{ml}$ syringe (see Note 2). The surface infiltrated appears darker at this point and should be outlined with a thin black marker pen to aid removal of correct segments of leaf for microscopy (for details see Fig.1).

9. Inoculated plants are then incubated under normal growth conditions for $48-72 \mathrm{~h}$ depending on the proteins expressed. This will have to be determined experimentally by checking the expression after e.g. 2, 3, and 4 days after infiltration.

10. Excised a $0.5 \times 0.5 \mathrm{~cm}$ piece of the infiltrated leaf and mount in a drop of water and observed with a microscope (see Note 3 and step 3.7).

11. Images can be recorded e.g. using a laser scanning confocal microscope with $\times 63$ or x100 high numerical aperture oil or water immersion objective lenses. For imaging of combinations of the green fluorescent (GFP) and red fluorescent protein (RFP), samples should be excited using 488 and $543 \mathrm{~nm}$ laser lines in multi-track mode preferably using line switching. Images can be analysed with proprietary software from the confocal manufacturer, with commercial image analysis software or freeware such as Fiji Image $\mathrm{J}$ (Fig. 2)

3.2 Stable transformation of tobacco from transiently expressing tobacco cells (13) 
1. Infiltrate at least two leaves on two different tobacco plants according to 3.1 and check the expression of the fusion protein by microscopy. If expression is low, then repeat infiltration until transformation levels are satisfactory and at least $70 \%$ of the cells in the field of view on the microscope are expressing the fusion protein.

2. Remove infiltrated leaves from the plant using scissors and immerse them completely into sterile $500 \mathrm{ml}$ beakers containing sterilization solution to remove trace amounts of Agrobacterium and other microbes from the leaf surface.

3. Carefully agitate the leaves for $8 \mathrm{~min}$ and then rinse them in a series of three sterile beakers containing sterile water (see Note 4).

4. Using scissors cut the leaves into pieces approximately $2 \times 2 \mathrm{~cm}$ avoiding the midrib (see Note 5).

5. Place the leaf squares onto agar plates of shooting medium plus the corresponding antibiotics for the transformation vector used and incubate at $25^{\circ} \mathrm{C}, 16 \mathrm{~h}$ light, $8 \mathrm{~h}$ dark, until shoots appear. This will take between 3-4 weeks.

6. Check regularly for contamination and, if apparent, transfer uncontaminated pieces to plates of fresh shooting medium.

7. When shoots are present, transfer them from the tissue with sterile forceps to plates with rooting medium. Roots will appear within 7-10 days.

8. Check again with the microscope for expression as there may be many shoots to deal with.

9. If the plants are expressing well, transfer them to Phytatrays or other suitable growth containers containing $0.5 \%$ Murashige and Skoog agar to develop until they are large enough to be transferred to soil.

\subsection{Transformation of arabidopsis using the floral dip method}

9.1. A $5 \mathrm{ml}$ liquid pre-culture, inoculated from single colony of Agrobacterium, carrying the appropriate binary vector, is grown with vigorous agitation (180 rpm) over night at $28^{\circ} \mathrm{C}$ with the appropriate antibiotics. 
9.2. $100 \mathrm{ml}$ of LB medium is inoculated with $1 \mathrm{ml}$ of the pre-culture and shaken over night at $28^{\circ} \mathrm{C}$ and $180 \mathrm{rpm}$.

9.3. Decant culture into two $50 \mathrm{ml}$ Falcon tubes.

9.4. Pellet the cells by centrifugation at $4^{\circ} \mathrm{C}$ with $4000 \mathrm{rpm}$ for $10 \mathrm{~min}$. Discard the supernatant and wash the resulting pellets by resuspension in $10 \mathrm{ml}$ infiltration medium.

9.5. The pelleting step is repeated and the two pellets are combined into one Falcon tube in a total of $50 \mathrm{ml}$ of dipping buffer.

9.6. Remove siliques from the inflorescence shoots from 2-4 plants of Arabidopsis thaliana (wild type Col-0) so only unfertilized flowers remain.

9.7. Dip the shoots upside down into the Falcon tubes containing the Agrobacteria suspension and soaked for $30 \mathrm{sec}$.

9.8. After dipping seal the plants with transparent plastic bags or cling film for the next $24 \mathrm{~h}$, then remove the cover and return plants to their normal growing conditions (see Note 6).

10. After 2-3 weeks the plants should not be watered anymore to allow the seeds to ripen. Plants with seeing heads should be bagged to stop loss of material or siliques grown through Aracon containers (Arasystem) to collect any loose seed.

11. Collect the seeds are brown and dry (approximately after about 6 weeks)

12. Selection of transformed arabidopsis plants is carried out by germinating seeds collected from transformed plants on MS plates containing $1 \%$ sucrose and the appropriate antibiotics or herbicide depending on the vector used.

\subsection{Immunofluorescence in Arabidopsis roots}

This protocol is designed for immuno-labelling of root tips, a similar method and also be used for fixing cells from suspension culture (e.g. BY2 cells).

1. Arabidopsis seedlings are grown vertically in Petri dishes for 5-7 days before fixation. The tips region (about $1 \mathrm{~cm}$ ) are collected and transferred into a plastic sieve (Fig. 3).

2. The fixative is prepared fresh each time. For making $10 \mathrm{ml}, 0.4 \mathrm{~g}$ of PFA is added to $5 \mathrm{ml}$ of $\mathrm{ddH}_{2} \mathrm{O}$ in a falcon tube. The mixture is warmed to $65^{\circ} \mathrm{C}$ in a water bath, and drops 
(about $20 \mu \mathrm{l}$ per $10 \mathrm{ml}$ ) of $0.1 \mathrm{M} \mathrm{NaOH}$ solution are added. The tube is agitates periodically until the PFA is dissolved. Cool the solution to room temperature, and add remaining buffer components. Bring the final volume to $10 \mathrm{ml}$ with $\mathrm{ddH}_{2} \mathrm{O}$. Finally, add Triton $\mathrm{X}-100$ to $0.01 \% \mathrm{v} / \mathrm{v}$ (see Note 7 ).

3. Fix roots for $90 \mathrm{~min}$, and then wash in PBS buffer 3 times for 5 min each.

4. Incubate roots in a Driselase solution $(2 \% \mathrm{w} / \mathrm{v})$ for $7 \mathrm{~min}$ at room temperature. Driselase solution is stored at $-20^{\circ} \mathrm{C}$. For each $1 \mathrm{ml}$ solution, add $10 \mu \mathrm{l}$ of PMSF $(100 \mathrm{mM}), 1 \mu \mathrm{l}$ of leupeptine $(10 \mathrm{mg} / \mathrm{ml})$, and $1 \mu \mathrm{l}$ of pepstatin $\mathrm{A}(1 \mathrm{mg} / \mathrm{ml})$ immediately before use (see Note 8). The protease inhibitors are there to block proteinases in the driselase solution.

5. Quickly wash roots in PBS 3 times, and incubate them for 15 min in PBS containing $0.1 \%$ Triton $\mathrm{X}-100$ to make cells permeable.

6. Quickly wash roots in PBS 3 times, and leave them in blocking buffer for $1 \mathrm{~h}$.

7. Incubate roots in primary antibody (diluted in blocking buffer, see Note 9) for 3-6 h at room temperature or over-night at $4^{\circ} \mathrm{C}$.

8. Wash roots in PBS buffer 3 times for 30 min each, and incubate them in secondary antibody solution for 1-3 h. Antibodies (e.g. FITC or TRITC conjugated) with minimal cross activity should be used for dual labelling, this is especially important for using primary antibodies raised in two close related species (e.g. rat and mouse, see Note 10).

9. Wash roots in PBS buffer 3 times for 30 min each (see Note 11), and mount the slide using Vectashield. Samples are now ready for microscopy.

10. In most cases, ER bodies, a spindle-like ER-derived structure, can be seen in wild type arabidopsis root cells. This can affect the visibility of the ER network (Fig. 3). To overcome this problem, an arabidopsis mutant without ER bodies (nai1, 17) can be used (Fig. 3).

11. If plants expressing GFP-HDEL are used for immunocytochemistry, the GFP signal can withstand fixation; therefore it can be used as a marker to test the co-localization of any protein of interest. As an example here, we use arabidopsis (nai1) roots expressing GFPHDEL, were immuno-stained with anti-NET3 ${ }^{\circ}$ (an ER-PM contact site protein). The result 
indicates the endogenous NET3C localized to punctate structure that co-aligned with the ER (see Note 12).

\subsection{Freeze-shattering and immunofluorescence}

This protocol is designed for immuno-labelling of whole plant tissue, ideally for leaf epidermal cells (11). It is based around using physical pressure on frozen material, after fixation, to fracture the cuticles and cell walls, thus enabling the easy penetration of antibodies.

1. Whole arabidopsis plantlets or excised leaves (10 days old) grown in Petri dishes can be used; they are pre-incubated for $15 \mathrm{~min}$ in MBS ester $(100 \mu \mathrm{M})$ solution. Transfer plants to fixative (supplemented with $100 \mu \mathrm{M}$ MBS ester) as described in section 3.4 for $1 \mathrm{~h}$.

2. After incubation, wash samples twice in PBS to remove all fixative. Transfer seedlings onto a glass slide and dry them using tissue paper. Put another glass slide on top to make a 'sandwich' (Fig. 3).

3. Rapidly freeze the 'sandwich' by immersion in liquid nitrogen, and place it in-between two metal blocks that are also cooled in liquid nitrogen (Fig. 3). Knock the top metal block gently with a hammer; this will shatter the arabidopsis seedlings into small pieces $(1 \mathrm{~mm}$ x $1 \mathrm{~mm}$, see Note 13).

4. Use cold tweezers to transfer plant pieces to a plastic sieve (Fig. 3). Then follow the protocol in section 3.4 (step 5-9) for antibody incubation.

5. Mount the slide using Vectashield or Citifluor antifade mountants. Samples are now ready for microscopy (Fig. 4).

3.6. Lipophilic dyes Rhodamine $\mathrm{B}$ hexyl ester or $\mathrm{DiOC}_{6}$ for live imaging of the $\mathrm{ER}$

1 Whole arabidopsis seedlings 7-10 days after germination are transferred to an Eppendorf tube containing the staining solution (Rhodamine $\mathrm{B}$ hexyl ester-1 $\mu \mathrm{M}$ or $\mathrm{DiOC}_{6}-1.8 \mathrm{mM}$ ) and incubated for 15 minutes for Rhodamine B or 10-30 min for $\mathrm{DiOC}_{6}$ (see Note 14). 
2 After incubation in the dye, transfer the seedlings to a fresh Eppendorf tube containing water to wash off excess staining solution.

3 Samples stained with Rhodamine B hexyl ester can be imaged with a 514-nm line of an argon ion laser using a 458/514 dichroic mirror, and the subsequent emission can be detected using 470- to 500-nm and 560- to 615-nm band-pass filters (Fig. 5).

4 Samples stained with $\mathrm{DiOC}_{6}$ should be imaged with a 488-nm line of an argon ion laser and emission can be detected at $492-629 \mathrm{~nm}$.

\subsection{Microscopy}

Whilst it is perfectly feasible to image fluorescent endoplasmic reticulum with a conventional wide-field epifluorescence microscope, the use of a point scanning or spinning disc confocal is recommended (18). For cortical ER in epidermal cells of living tissue it is also possible to obtain excellent images with a TIRF (Total Internal Reflection Fluorescence microscopy) (19).

\section{Notes}

1. Concentrated stock solution of PIPES, EGTA and $\mathrm{MgSO}_{4}$ can be made, aliquoted and stored at $-20^{\circ} \mathrm{C}$.

2. Try to avoid large veins. A small hole may be punched into the lower epidermis to aid infiltration.

3. For use with an inverted microscope it can be useful to stick coverslips to the slide with a tape such as electrical tape, in order to prevent movement of the coverslip and specimen during observation of the specimen.

4. Make sure the leaves are not damaged by hypochlorite and shorten the exposure time to a minimum of $5 \mathrm{~min}$ if necessary. Incubations longer than $8 \mathrm{~min}$ will be detrimental to the tissue, resulting in cell death. 
5. From this step on throughout the following tissue culture steps proper sterile techniques need to be applied.

6. The same plants can be dipped again about 5-7 days after the first dipping, which can dramatically increase the transformation efficiency. Note: do not cut any siliques for the second dipping as they might already have been successfully transformed in the first round.

7. The concentration of Triton $\mathrm{X}-100$ is critical here, especially for fixing fragile ER network. High levels of detergent can destroy the membrane structure and produce fragmented ER.

8. After enzyme treatment, handle the roots gently to avoid loss of tips.

9. Dilution factors vary for different antibody, 1:100-200 is recommended to start with. For the experiments described here, about 200-300 $\mu$ l of antibody solution was sufficient to cover root in the plastic sieve.

10. For negative controls, omit the primary antibody and the secondary antibody only sample should not produce any signal. Likewise with anti-peptide antibodies, the antibody in the serum can be titrated out through addition of the peptide.

11. For nuclear staining, PBS supplemented with $10 \mathrm{ng} / \mathrm{ml}$ DAPI or Hoechst can be used after the second wash.

12. The ER network is cisternalised in cells from root tips, and these cells are small. Therefore, it can often be difficult to resolve the ER membrane from the cytoplasmic signals.

13. Only a gently tap with the hammer is required. Wear eye protection when handling liquid nitrogen.

14. Low concentrations of $\mathrm{DiOC}_{6}$ will label mitochondria.

\section{References}


1. Wang P, Hawkins TJ, Richardson C, Cummins I, Deeks MJ, Sparkes I, Hawes C, Hussey PJ (2014) The plant cytoskeleton, NET3C, and VAP27 mediate the link between the plasma membrane and endoplasmic reticulum. Curr Biol 24:1397-1405

2. Boevink P, Santa Cruz S, Hawes C, Harris N, Oparka KJ (1996). Virus mediated delivery of the green fluorescent protein to the endoplasmic reticulum of plant cell. The Plant Journal 10:35-941

3. Terasaki M, Song J, Wong JR, Weiss MJ, Chen LB (1984) Localization of endoplasmic reticulum in living and glutaraldehyde-fixed cells with fluorescent dyes. Cell 38:101-108

4. Quader H, Schnepf E (1986) Endoplasmic reticulum and cytoplasmic streaming: fluorescence microscopical observations in adaxial epidermis cells of onion bulb scales. Protoplasma 131:50-252

5. Sparkes I, Tolley N, Aller I, Svozil J, Osterrieder A, Botchway S, Mueller C, Frigerio L, Hawes C (2010) Five Arabidopsis reticulon isoforms share endoplasmic reticulum location, topology, and membrane-shaping properties. Plant Cell 22:1333-43

6. Huang LQ, Franklin AE, Hoffman NE (1993) Primary structure and characterization of an Arabidopsis thaliana calnexin-like protein. Journal of Biological Chemistry 268:6560-6566

7. Ivanov S, Harrison MJ (2014) A set of fluorescent protein-based markers expressed from constitutive and arbuscular mycorrhiza-inducible promoters to label organelles, membranes and cytoskeletal elements in Medicago truncatula. Plant J 80:1151-63

8. Lee H, Sparkes I, Gattolin S, Dzimitrowicz N, Roberts LM, Hawes C, Frigerio L (2013) An Arabidopsis reticulon and the atlastin homologue RHD3-like2 act together in shaping the tubular endoplasmic reticulum. New Phytol 197:481-419

9. Denecke J, De Rycke R, Botterman J (1992) Plant and mammalian sorting signals for protein retention in the endoplasmic reticulum contain a conserved epitope. EMBO J $11: 2345-55$.

10. Gomord V, Denmat LA, Fitchette-Lainé AC, Satiat-Jeunemaitre B, Hawes C, Faye L (1997) The C-terminal HDEL sequence is sufficient for retention of secretory proteins in the 
endoplasmic reticulum (ER) but promotes vacuolar targeting of proteins that escape the ER. Plant J 11:313-325

11. Satiat-Jeunemaitre B, Hawes C (2001) Immunocytochemistry for light microscopy. Pp. 207-233 Chapter 10 in Plant Cell Biology: Practical Approach (eds. C Hawes and B SatiatJeunemaitre. O.U.P. New York

12. Wasteneys $G$ (1997) Freeze shattering: a simple and effective method for permeabilizing higher plant cell walls. J Microsc 188:51-61

13. Wang P, Richardson C, Hawkins TJ, Sparkes I, Hawes C, Hussey PJ. (2016) Plant VAP27 proteins: domain characterization, intracellular localization and role in plant development. New Phytol 210:1311-1326

14. Sparkes IA, Runions J, Kearns A, Hawes C (2006) Rapid, transient expression of fluorescent fusion proteins in tobacco plants and generation of stably transformed plants. Nat Protoc 1:2019-2025

15. Kriechbaumer V, Shaw R, Mukherjee J, Bowsher CG, Harrison AM, Abell BM (2009) Subcellular distribution of tail-anchored proteins in Arabidopsis. Traffic 10:1753-1764 16. Karimi M, De Meyer B, Hilson P (2005) Molecular cloning in plant cells. Trends Plant Sci 10:103-105

17. Kriechbaumer V, Botchway SW, Slade SE, Knox K, Frigerio L, Oparka K, Hawes C (2015) Reticulomics: Protein-protein interaction studies with two plasmodesmata-localized reticulon family proteins identify binding partners enriched at plasmodesmata, endoplasmic reticulum, and the plasma membrane. Plant Physiology 169:1933-1945

18. Matsushima R, Fukao Y, Nishimura M, Hara-Nishimura I (2004) NAl1 gene encodes a basic-helix-loop-helix-type putative transcription factor that regulates the formation of an endoplasmic reticulum-derived structure, the ER body. Plant Cell 16:1536-1549 19. Pawley JB (2006) Handbook of Biological Confocal Microscopy. Springer Science+Business Media, New York 
20. Vizcay-Barrena G, Webb SED,Martin-Fernandez ML, Wilson ZA (2011) Subcellular and single-molecule imaging of plant fluorescent proteins using total internal reflection fluorescence microscopy (TIRFM). Journal of Experimental Botany 62:5419-5428

21. Kriechbaumer V, Botchway SW, Hawes C (2016) Localization and interactions between Arabidopsis auxin biosynthetic enzymes in the TAA/YUC-dependent pathway. Journal of Experimental Botany 67:4195-207 


\section{Figure legends:}

Figure 1. Infiltration of tobacco epidermal leaf cells with Agrobacterium tumefaciens. (A) A hole is punched into a leaf section using a $100 \mu$-pipette tip. (B) The bacterial suspension culture is carefully pressed into the leaf by covering the hole with a $1 \mathrm{ml}$ syringe on the lower epidermal site and a finger on the upper side. (C) As much as possible of that leaf section is filled with the culture. (D) The infiltrated parts will show up darker now. $(E)$ Mark the infiltrated area with a pen. (F) Infiltrate as many leaf sections as required for the constructs tested.

Figure 2. GFP-labelled ER in tobacco leaf epidermal cells.

The ER network is labelled with the ER membrane localized protein TAR2 (20) fused to GFP as a fluorophore and visualized using confocal microscopy. Size bar $=10 \mu \mathrm{m}$

Figure 3. Experiment set-up for immune-labelling (a) and freeze-shattering (b).

Figure 4. Immuno-labelling of the ER network from different cell types. (a) The ER network is labelled with anti-HDEL in combination with a FITC-conjugated secondary antibody; ER bodies can be identified throughout the cell. (b) Arabidopsis mutant (nai 1) transformed with GFP-HDEL do not produce ER bodies. The GFP-HDEL labelled ER network is still strong after fixation. The ER network from root meristem cells and a dividing cell at the anaphase is shown. For both (a) and (b), nucleus are stained with DAPI. (c) GFPHDEL expressing root cells (nai 1) are fixed and stained with anti-NET3C in combination with a TRITC-conjugated secondary antibody. As demonstrated, NET3C labelled punctate structures are localised to the ER network. (d) After freeze shattering, arabidopsis leaf epidermal cells are stained with anti-BIP2 (ER) and anti-VAP27-1 (ER and ER-PM contact sites) antibodies. The ER structure is much clear and defined in leaf cells than in root tips. 
Figure 5. Confocal image of arabidopsis reticulon6 mutant dyed with Rhodamine B hexyl ester.

The ER network is stained with the dye Rhodamine B hexyl ester and visualized using confocal microscopy. Size bar $=5 \mu \mathrm{m}$ 